- 研究报告・

\title{
滇西南四个自然保护区鱼类多样性及评价指标探究
}

\author{
周 伟* 李明会 李有兰 \\ (西南林业大学云南省森林灾害预警与控制重点实验室, 昆明 650224)
}

\begin{abstract}
摘要: 为了解滇西南怒江水系的南滚河自然保护区、南捧河自然保护区、永德大雪山自然保护区及澜沧江水系的 澜沧江自然保护区鱼类多样性和变化趋势, 探讨其差异和变化的原因, 本文采用 $\beta$ 多样性指数分析了 4 个保护区的 鱼类多样性, 并比较了鱼类分类阶元的特有性、单型性和古老成分的有无等多项指标。结果显示, 4 个自然保护区 共有土著鱼类 85 种, 隶属于 6 目 13 科 45 属。在中国仅见于怒江水系的 4 个特有属有异鲖属(Aspidoparia) 和新条䱊属 (Neonoemacheilus) 分布于这 3 个保护区中; 18 种特有种中, 仅分布在这 3 个保护区的狭域特有种 5 种。在中国仅分布 于澜沧江水系的属有 31 个, 但仅安巴沙鱾属(Ambastaia) 分布于澜沧江保护区; 在澜沧江保护区分布着中国仅见于 澜沧江水系的特有种 20 种, 其中狭域特有种 3 种。怒江水系的 3 个保护区分布有 1 个单型属, 即䲛鲡属(Anguilla), 但 没有单型种; 澜沧江自然保护区无单型属与单型种分布。4个保护区中的鱼类均系晚第三纪和第四纪形成的种类或 类群，没有古老或子遗种类。 $\beta$ 多样性结果显示，在 4 个保护区中澜沧江自然保护区的鱼类多样性最丰富，而南滚河 自然保护区的丰富程度最低, 但是怒江水系3个自然保护区鱼类多样性的代表性及保护地位比澜沧江自然保护区 的要高。而特有阶元和单型性阶元的存在体现出怒江水系 3 个自然保护区的保护价值及保护意义比澜沧江保护区 高。地理范围跨度大小、生境空间异质性高低、保护区面积大小及支流多少等是影响鱼类多样性的主要因素。因 此, 规划和设计保护区时, 如果能在水系的上、中、下游分别规划 1 条一级支流作为保护区, 可使该水系的绝大多 数鱼类得到保护。
\end{abstract}

关键词: 鱼类多样性; 单型性; 特有性; $\beta$ 多样性指数; 滇西南

\section{Fish diversity in four nature reserves in Southwest Yunnan, China and the evaluation indicators}

\author{
Wei Zhou*, Minghui Li, Youlan Li \\ Key Laboratory of Forest Disaster Warning and Control in Yunnan Province, Southwest Forestry University, Kunming
} 650224

\begin{abstract}
This study investigated the diversity of fish species in the Nangunhe, Nanpenghe, Yongde Daxueshan and Lancangjiang nature reserves in Southwest Yunnan, China. The $\beta$ diversity index, current and ancient endemic and monotypic taxa of inhabitants were used to compare the differences in present and historic fish species and genera composition among the nature reserves. The mechanisms behind difference in fish species diversity among the nature reserves were also investigated. We recorded 85 extant native species, belonging to 6 orders, 13 families, and 45 genera. There are four endemic genera and 18 endemic species being observed in Nujiang River system in China. The genera Aspidoparia and Neonoemacheilus and five endemic species occurred in these three nature reserves (Nangunhe, Nanpenghe, Yongde Daxueshan reserves). There have been 31 genera occurred only in the Lancangjiang River system in China, but the only genus observed in the Lancangjiang Nature Reserve was Ambastaia. In China twenty species were observed only in Lancangjiang Nature Reserve, three of which were only found in this reserve. Among the three nature reserves within the Nujiang river system, only one monotypic genus Anguilla and no monotypic species were observed. No monotypic genera or species were observed in the Lancangjiang Nature Reserve. Comparisons of observed species and groups with fossil records show that the current fishes of Yunnan are species and groups
\end{abstract}

收稿日期: 2015-12-23; 接受日期: 2016-03-01

基金项目: 国家自然科学基金(31160419)和西南林业大学云南省省级重点学科(林学)支持

* 通讯作者 Author for correspondence. E-mail: weizhouyn@163.com 
that evolved in the later Tertiary and Quaternary periods, and there are no old or relic species currently present. The $\beta$ diversity index showed that fish diversity was greatest in the Lancangjiang Nature Reserve, and the lowest in the Nangunhe Nature Reserve. However, the fish diversity representation and protected status in the three nature reserves located within the Nujiang River system are higher than those in the Lancangjiang Nature Reserve. The existence of monotypic species and taxa in the three nature reserves within the Nujiang River system reflects the importance of fisheries protection within these reserves. Geographical location, the length, heterogeneity, number of river branches in the reserve explained difference in fish diversity among the four nature reserves. In order to provide protection to the greatest number of fish species, the first branches in the upper, middle and lower regions of the river system should be designated as reserves.

Key words: fish diversity; monotypic; endemic; $\beta$ diversity index; Southwest Yunnan

国内鱼类多样性研究通常是对特定水系、支流 或湖泊的鱼类区系及其与水系的渊缘关系等问题 进行研究和探讨(杨君兴等，1994; 陈宜瑜，1998); 或者用 $\alpha$ 多样性指数 (如 Shannon-Wiener 指数、 Simpson指数和Margalef丰富度指数等)分析鱼类群 落的丰富度和多样性, 探讨干流与支流多样性指数 的变化规律以及栖息环境的变化对群落中优势种 类组成的影响和变化等(陈自明等, 2006; 苏国欢等, 2015 ; 肖琼等, 2015); 或者是运用 $\beta$ 多样性指数对某 一水系或同一水系不同支流鱼类的多样性进行比 较, 以反映鱼类种、属的分化和隔离程度, 探讨导 致鱼类多样性差异的原因(周伟等, 1999; 李凤莲等, 2006; 周小愿等, 2011)。这些研究运用不同多样性 指数研究了鱼类多样性现状, 而对相邻水系鱼类多 样性的比较研究甚少, 更未见对鱼类多样性究竟该 如何评价才能反映其来源、组成和演化趋势等的 研究。

与怒江水系相连的云南南滚河国家级自然保 护区、云南南捧河省级自然保护区和云南永德大雪 山国家级自然保护区以及位于澜沧江中段的云南 澜沧江省级自然保护区等 4 个保护区 (以下分别简称 为南滚河保护区、南捧河保护区、永德大雪山保护 区、澜沧江保护区), 均位于北回归线南北两侧, 地 理位置特殊, 鱼类多样性高 (陈小勇等, $2003^{1}$, , 2007; 周伟等, 2004, 2012 (2) 。如果仅分析鱼类的区 系组成、相似性和 $\alpha$ 多样性指数, 不足以说明这 4 个 保护区在保护怒江和澜沧江水系鱼类多样性方面

(1) 陈小勇, 蒋万胜, 杨君兴 (2003) 第 10 章 鱼类. 见: 云南省林业调 查规划设计院等. 中国云南永德国家级自然保护区综合科学考察报告 (手稿).

(2) 周伟, 杨琴, 刘恺, 徐万吉 (2012) 第 13 章 鱼类. 见: 杜凡等主编. 云南南捧河省级自然保护区综合科学考察报告(手稿).
的作用及地位。如果以 $\beta$ 多样性指数为基础，同时考 虑反映鱼类多样性地位的其他指标, 则有助于了解 该区域鱼类种属组成差异及其原因，为今后制定自 然保护区鱼类多样性的保护规划、研究资源持续利 用提供参考。

\section{1 研究区域概况}

南滚河保护区成立于1980年，位于云南省临沧 市沧源㑑族自治县西北部班洪、班老两乡境内 $\left(98^{\circ} 57^{\prime}-99^{\circ} 05^{\prime} \mathrm{E}, 23^{\circ} 13^{\prime}-23^{\circ} 19^{\prime} \mathrm{N}\right)$, 呈东北-西南走 向。1981年5月划定保护区时面积为6,671 ha, 1987 年保护区边界调整后其总面积为 7,082.5 ha，水系 仅包括怒江水系的一级支流南滚河。1995年被确认 为国家级自然保护区，周伟等(2004)调查记录鱼类 30 种，隶属于5目9科 21 属。2003年国务院批准对该 保护区扩建，面积达到 $50,887.0 \mathrm{ha}$, 横跨沧源㑑族 自治县和耿马傣族和㑑族自治县 (98 $57^{\prime} 32^{\prime \prime}-$ 99 $\left.26^{\prime} 00^{\prime \prime} \mathrm{E}, 23^{\circ} 09^{\prime} 12^{\prime \prime}-23^{\circ} 40^{\prime} 08^{\prime \prime} \mathrm{N}\right)$, 水系也扩增到 澜沧江水系，而怒江水系的一级支流南汀河、南碧 河等也被囊括进来(唐芳林等, 2015)。但为了方便水 系/支流比较的缘故, 本次研究区域仅限于1995年 时的南滚河国家级自然保护区范围。

南捧河保护区位于云南省临沧市镇康县, 分为 竹瓦、忙丙后箐、薄刀山和雪竹林山等 4 个片区 $\left(98^{\circ} 41^{\prime}-99^{\circ} 18^{\prime}\right.$ E、 $\left.23^{\circ} 45^{\prime}-24^{\circ} 04^{\prime} \mathrm{N}\right)$, 总面积 36,970 ha。周伟等 $(2012)^{(2)}$ 调查记录鱼类49种, 隶属于 6 目 12 科28属。

永德大雪山保护区位于云南省临沧市永德县

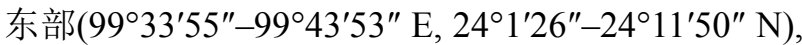
总面积约15,900 ha。陈小勇等(2003) 结合野外采集 的标本、访谈记录及周边地区鱼类资源记录, 统计 
该保护区共有鱼类 57 种, 隶属于 5 目 14 科 43 属。

澜沧江保护区位于澜沧江流域中部的云南省 临沧市境内 $\left(99^{\circ} 07^{\prime}-100^{\circ} 25^{\prime} \mathrm{E}, 23^{\circ} 07^{\prime}-25^{\circ} 02^{\prime} \mathrm{N}\right)$, 跨 凤庆、云县、临沧、耿马和双江5县, 保护区从北到 南依次有五道河、小湾-黄竹岭、大丙山、万明山大钟山、临沧大雪山、帮骂雪山和马鞍山等7个片 区，总面积为 $75,186 \mathrm{ha}$, 水系属于澜沧江水系。澜 沧江中游记录鱼类 6 目 15 科 48 属 76 种 (陈小勇等, 2007)。

\section{2 方法}

\section{1 数据来源}

基础鱼类名录来自 4 个自然保护区已公开发表 的考察报告(陈小勇等, 2007; 周伟等, 2004) ${ }^{[122}$ 或手 稿。在此基础上, 根据西南林业大学动物学标本室 保存的鱼类标本对名录进行补充完善。最后将基本 名录与陈小勇(2013)的工作比对, 修改、订正、补充 和完善, 剔除外来种, 仅保留土著种。

\section{2 群落多样性分析}

将每一条河流/支流视为 1 个样本/群落, 本文的 4 个保护区视为 4 个样本/群落(周伟等, 1999)。

(1)选择Cody指数 $\left(\beta_{\mathrm{c}}\right)$ 比较 2 个保护区间新增加 和失去的物种数, 以反映不同保护区间的生境差异 和变化(Cody, 1975), 公式如下:

$$
\beta_{\mathrm{c}}=(g+l) / 2
$$

式中, $g$ 指仅出现在保护区A中的物种数(或属数); $l$ 指仅出现在保护区 $\mathrm{B}$ 中的物种数(或属数)。

(2) 用Routledge指数 $\left(\beta_{\mathrm{R}}\right)$ 指示 2 个保护区物种的 分化和隔离程度(Routledge, 1977), 公式如下:

$$
\beta_{\mathrm{R}}=\left[S^{2} / 2 r+S\right]-1
$$

式中, $S$ 为 2 个保护区鱼类物种总数(或属的总数); $r$ 为 2 个保护区共有的物种数(或属数)。

(3) 用 Jaccard相似性指数 $\left(C_{\mathrm{J}}\right)$ 比较 2 个保护区之 间鱼类组成的相似程度; 也可以用Sorenson相异性 指数 (index of dissimilarity, $C_{\mathrm{s}}$ ) 来估计 (Magurran, 1988), 公式分别为:

$$
\begin{aligned}
& C_{\mathrm{J}}=j /(a+b-j) \\
& C_{\mathrm{s}}=2 j /(a+b)
\end{aligned}
$$

(1) 陈小勇, 蒋万胜, 杨君兴 (2003) 第10章 鱼类. 见: 云南省林业调查 规划设计院等. 中国云南永德国家级自然保护区综合科学考察报告(手 稿).

(2) 周伟, 杨琴, 刘恺, 徐万吉 (2012) 第13章 鱼类. 见: 杜凡等主编. 云南南捧河省级自然保护区综合科学考察报告(手稿).
式中, $j$ 为两个群落(或保护区)共有的种数(或属数); $a$ 和 $b$ 分别为群落(或保护区) $\mathrm{A}$ 和 $\mathrm{B}$ 的物种数(或属 数)。

鉴于 4 个保护区间鱼类目和科的数量差别不大, 因此本文只从属和种两个层次计算 $\beta$ 多样性指数。 采用Excel 2003完成计算和分析。

\section{3 反映多样性的其他指标}

一个区域内是否拥有特有和单型性分类阶元， 以及区系成分是否古老等皆是衡量该区域生物多 样性是否丰富及价值高低的客观指标。它们不仅反 映和记录了一个区域在生物区系形成和演化过程 中的历史及重要性，还体现了该区域(或者说区域 中所包含的各个自然保护区)对鱼类多样性保护的 意义。

查询国际鱼类数据库 Catalog of Fishes (http://researcharchive.calacademy.org/research/ichthy ology/catalog/fishcatmain.asp), 确定鱼类名录中是 否有单型种和单型属, 是否存在着在中国仅分布于 澜沧江水系和怒江水系的特有种、属, 甚至分布范 围更为狭窄而仅分布于保护区的狭域特有种、属。

鱼类最早出现于奥陶纪, 繁盛于泥盆纪。在新 生代第三纪或更早曾广泛分布, 而目前大部分物种 /类群已灭绝，仅极少被保存下来的子遗种类可算 作是古老成分。据鱼类化石研究资料, 尤其是云南 鱼类化石研究的资料来确定 4 个自然保护区鱼类是 否具有古老成分(陈银瑞和崔桂华, 1989)。

\section{3 结果}

\section{1 鱼类区系组成的基本特征 \\ 3.1.1 分类阶元组成}

经整理, 4 个自然保护区共有土著鱼类 85 种, 分 隶于 6 目 13 科 45 属(附录1)。澜沧江保护区的鱼类属 种数不仅多于怒江水系任一保护区的属种数, 也多 于 3 个保护区合起来的属种数。怒江水系 3 个保护区 中, 以南滚河保护区的鱼类属种数最少 (表1)。但是 从保护区拥有分类阶元数占其所属水系的分类阶 元数的百分比来看, 怒江水系 3 个保护区的百分比 要高得多, 即它们所拥有的分类阶元的代表性比澜 沧江保护区的代表性要高许多(表2)。

澜沧江水系鱼类缺鳗鲭目, 而怒江水系缺领针 鱼目。虽然怒江水系 3 个自然保护区的河流仅属于 怒江水系的一小部分, 但却分布有怒江水系鱼类大 
表1 滇西南 4 个自然保护区中两两之间的鱼类独有类群数和共有类群数

Table 1 Taxa shared only by a reserve or two reserves when compared among four nature reserves in Southwest Yunnan

\begin{tabular}{|c|c|c|c|c|c|c|c|c|c|c|c|c|}
\hline & \multicolumn{3}{|c|}{$\begin{array}{l}\text { 南滚河保护区 } \\
\text { Nangunhe Reserve }\end{array}$} & \multicolumn{3}{|c|}{$\begin{array}{l}\text { 南捧河保护区 } \\
\text { Nanpenghe Reserve }\end{array}$} & \multicolumn{3}{|c|}{$\begin{array}{l}\text { 永德大雪山保护区 } \\
\text { Yongde Daxueshan Reserve }\end{array}$} & \multicolumn{3}{|c|}{$\begin{array}{l}\text { 澜沧江保护区 } \\
\text { Lancangjiang Reserve }\end{array}$} \\
\hline & 科 ${ }^{\mathrm{F}}$ & 属 $^{\mathrm{G}}$ & 种 $\mathrm{S}$ & 科 $\mathrm{F}$ & 属 $^{\mathrm{G}}$ & 种 $\mathrm{S}$ & 科 $\mathrm{F}^{2}$ & 属 ${ }^{\mathrm{i}}$ & 种 $^{\mathrm{S}}$ & 科 $\mathrm{F}$ & 属 $\mathrm{G}$ & 种 $^{\mathrm{S}}$ \\
\hline & 8 & 24 & 33 & 10 & 29 & 41 & 10 & 28 & 35 & 12 & 36 & 54 \\
\hline \multicolumn{13}{|l|}{ 独有类群数 Taxa shared only by a reserve } \\
\hline 南滚河保护区 Nangunhe Reserve & - & - & - & 0 & 2 & 5 & 1 & 3 & 10 & 1 & 7 & 18 \\
\hline 南捧河保护区 Nanpenghe Reserve & 2 & 7 & 13 & - & - & - & 1 & 6 & 14 & 1 & 8 & 24 \\
\hline 永德大雪山保护区 Yongde Daxueshan Reserve & 3 & 7 & 12 & 1 & 5 & 8 & - & - & - & 1 & 9 & 25 \\
\hline 澜沧江保护区 Lancangiiang Reserve & 5 & 19 & 39 & 3 & 15 & 37 & 3 & 16 & 43 & - & - & - \\
\hline \multicolumn{13}{|l|}{ 共有类群数 Taxa shared by two reserves } \\
\hline \multicolumn{13}{|l|}{ 南滚河保护区 Nangunhe Reserve } \\
\hline 南捧河保护区 Nanpenghe Reserve & 8 & 22 & 28 & & & & & & & & & \\
\hline 永德大雪山保护区 Yongde Daxueshan Reserve & 7 & 21 & 23 & 9 & 23 & 27 & & & & & & \\
\hline 澜沧江保护区 Lancangjiang Reserve & 7 & 17 & 17 & 9 & 17 & 21 & 9 & 13 & 20 & & & \\
\hline
\end{tabular}

F, family; G, genus; S, species.

表2 保护区与隶属水系鱼类分类阶元的比较

Table 2 Fish category comparisons between the reserves and its drainage

\begin{tabular}{|c|c|c|c|c|c|c|}
\hline \multirow{2}{*}{$\begin{array}{l}\text { 阶元 } \\
\text { Category } \\
\text { 目 Order }\end{array}$} & \multicolumn{2}{|c|}{$\begin{array}{c}\text { 南捧河保护区阶元数/怒江水系 } \\
\text { 的阶元数及百分比 } \\
\text { Fish taxa from Nanpenghe Reserve/ } \\
\text { taxa from Nujiang (\%) }\end{array}$} & \multicolumn{2}{|c|}{$\begin{array}{c}\text { 怒江水系3个保护区阶元数/怒江水系 } \\
\text { 的阶元数及百分比 } \\
\text { Fish taxa from } 3 \text { reserves of Nujiang/taxa } \\
\text { from Nujiang (\%) }\end{array}$} & \multicolumn{2}{|c|}{$\begin{array}{c}\text { 澜沧江保护区阶元数/澜沧江水系 } \\
\text { 的阶元数及百分比 } \\
\text { Fish taxa from Lancangjiang Reserve/ } \\
\text { taxa from Lancangjiang (\%) }\end{array}$} \\
\hline & $5 / 6$ & 83.3 & $5 / 6$ & 83.3 & $5 / 7$ & 71.4 \\
\hline 科 Family & $10 / 13$ & 76.9 & $11 / 13$ & 84.6 & $12 / 22$ & 54.5 \\
\hline 属 Genus & $29 / 51$ & 56.9 & $36 / 51$ & 70.6 & $36 / 93$ & 38.7 \\
\hline 种 Species & $41 / 77$ & 53.2 & $54 / 77$ & 70.1 & $54 / 183$ & 29.5 \\
\hline
\end{tabular}

部分分类阶元的代表类型。3个保护区间比较，分类 阶元的等级越高, 相同类群的数目越多; 反之, 分 类阶元等级越低, 相同数目越少。从另一角度看, 以南捧河为例, 将该保护区鱼类分类阶元与怒江水 系比较, 发现和 3 个保护区与怒江水系在目、科这两 级的比值差别不大, 而属、种这两级的差别就比较 明显(表2)。表明随着分类等级的降低, 南捧河 1 个保 护区拥有的鱼类不同分类等级相对于整个水系同 等分类等级的代表性在降低。怒江水系 3 个保护区 鱼类不同分类等级相对于怒江水系的代表性均高 于澜沧江保护区相对于澜沧江水系的代表性。结果 一方面表明, 与怒江水系相比, 澜沧江水系分布的 科、属和种数量多; 另一方面表明, 多个保护区鱼 类分类等级代表性高于 1 个保护区的代表性。

\subsection{2 古老成分}

根据化石资料记录, 云南现生鱼类皆为第三纪
和第四纪起源和形成的鱼类区系或由它们演化形 成的后裔类群/种类。所以, 这 4 个保护区中没有古 老或子遗种类。

\subsection{3 特有成分}

在中国无仅见于怒江一萨尔温江流域的特有目 和科, 但具有仅见于该水系的特有属 4 个, 即异鱽 属 (Cabdio)、角鱼属 (Akrokolioplax)、新条鱾属 (Neonoemacheilus) 和黑鮡属(Gagata), 其中在怒江 水系的 3 个保护区中分布有 2 个属, 即异鲖属和新条 鳅属，占整个怒江水系特有属的 $50 \%$ 。种级阶元上， 怒江水系的 3 个保护区分布着中国仅见于怒江水系 的特有种 18 种, 其中狭域特有种 5 种, 即少斑褶鮡 (Pseudecheneis paucipunctatus) 为南滚河保护区特 有; 南汀爬鲀(Balitora nantingensis)为南捧河保护 区特有; 异斑南鳅 (Schistura disparizona) 为南滚河 与南捧河保护区特有; 无斑异齿鰋(Oreoglanis im- 
maculatus)为南滚河与永德大雪山保护区特有; 南 定南鳅(Schistura nandingensis)为南捧河与永德大 雪山保护区特有(附录1)。

在中国无仅见于澜沧江水系的特有目分布, 具 有仅见于澜沧江水系的特有科 3 个, 即双孔鱼科、 鲻科和粒鲇科, 但在澜沧江保护区中无这 3 科鱼类 分布。在中国仅分布于澜沧江水系的属有 31 个, 但 仅安巴沙鳅属(Ambastaia)分布于澜沧江保护区。在 澜沧江保护区的种级阶元中, 有 20 种为中国仅见于 澜沧江水系的特有种, 占整个保护区内鱼类总数的 $35.7 \%$, 其中仅分布在澜沧江中游的鱼类, 即狭域 特有种有张氏间吸鳅(Hemimyzon zhangi)、云南孟加 拉鲮 (Bangana yunnanensis) 和奇额墨头鱼 (Garra mirofronits)等3种分布在保护区(附录1)。

\subsection{4 单型阶元}

澜沧江保护区无单型种与单型属分布; 怒江水 系的3个保护区有1个单型属鳗鲡属(Anguilla)分布, 但无单型种分布(附录1)。

\subsection{5 分类阶元数与保护区面积的关系}

4个自然保护区鱼类种、属数量与保护区面积 的比值表明, 种、属数量的多寡与保护区的面积不
成正比关系，其中南滚河保护区单位面积拥有的 种、属数量最多; 而澜沧江保护区的单位面积拥有 的种、属数量最少(表3)。

\section{2 鱼类多样性测度分析}

4 个保护区鱼类群落的 $\beta$ 多样性分析结果表明, 澜沧江保护区的鱼类 $\beta$ 多样性指数 $\left(\beta_{\mathrm{c}}\right.$ 和 $\left.\beta_{\mathrm{R}}\right)$ 与怒江水 系3个自然保护区相比皆是最高的; 相反, 怒江水 系 3 个保护区之间的 $\beta$ 多样性指数 $\left(\beta_{\mathrm{c}}\right.$ 和 $\left.\beta_{\mathrm{R}}\right)$ 小许多。此 外, 怒江水系 3 个保护区的鱼类 $\beta$ 多样性指数随着纬 度增加呈递增趋势(表4)。

相似性指数结果显示, 澜沧江保护区与怒江水 系 3 个保护区相比, Jaccard 相似性指数 $\left(C_{\mathrm{J}}\right)$ 和 Sorenson相异性指数 $\left(C_{\mathrm{s}}\right)$ 均较低, 怒江水系 3 个保护 区之间的相似性指数随着纬度增加呈递减趋势。属 级阶元的相似性指数与种级阶元的相似性指数无 直接的关系, 即在某个变化梯度中, 属级阶元指数 并不一定随着种级阶元指数的变化而变化(表4)。

\section{4 讨论}

\section{1 生境差异及其物种隔离分化}

$\beta$ 多样性指数既反映群落(保护区)间的生境差

表3 滇西南 4 个自然保护区种数和属数与保护区面积的关系

Table 3 The relationship between species or genera and reserve area of four nature reserves in Southwest Yunnan

\begin{tabular}{lcccc}
\hline & $\begin{array}{c}\text { 南滚河保护区 } \\
\text { Nangunhe Reserve }\end{array}$ & $\begin{array}{c}\text { 南捧河保护区 } \\
\text { Nanpenghe Reserve }\end{array}$ & $\begin{array}{c}\text { 永德大雪山保护区 } \\
\text { Yongde Daxueshan Reserve }\end{array}$ & $\begin{array}{c}\text { 澜沧江保护区 } \\
\text { Lancangjiang Reserve }\end{array}$ \\
\hline 保护区面积 Reserve area (ha) & $7,082.5$ & 36,970 & 15,900 & 75,186 \\
种数/保护区面积 Species/reserve area & 0.0047 & 0.0011 & 0.0022 & 0.0007 \\
属数/保护区面积 Genera/reserve area & 0.0034 & 0.0008 & 0.0018 & 0.0005 \\
\hline
\end{tabular}

表4 四个自然保护区鱼类物种/属数 $\beta$ 多样性

Table 4 Fish $\beta$ diversity index in species/genera level among four nature reserves

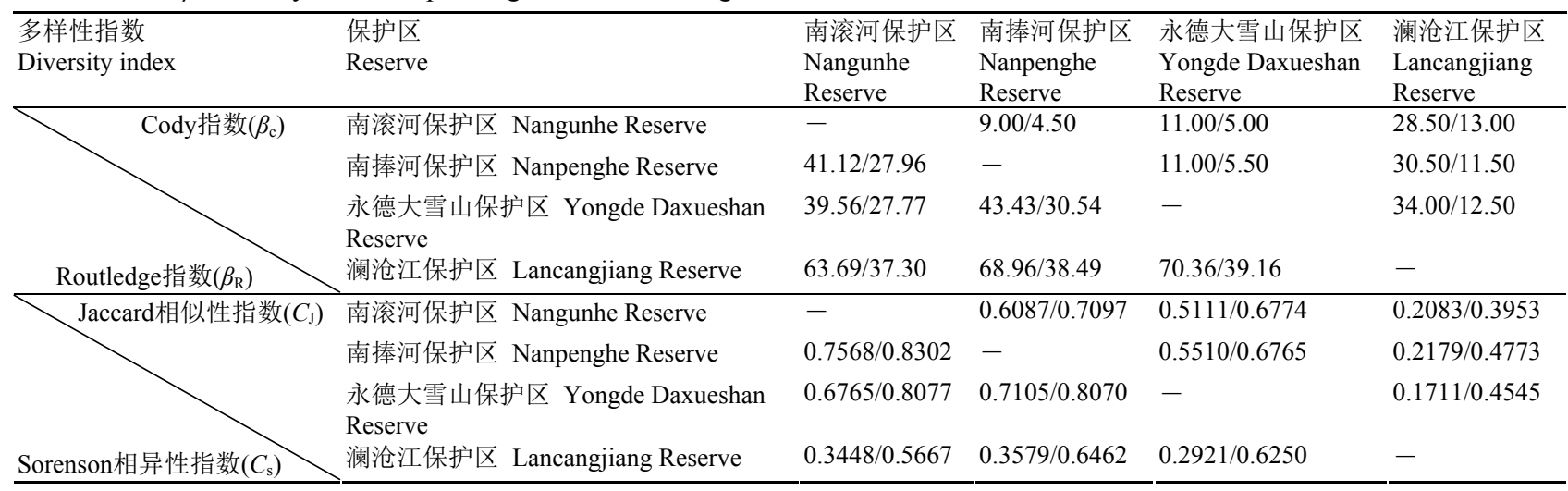

$\beta \mathrm{c}$, Cody index; $\beta_{\mathrm{R}}$, Routledge index; $C_{\mathrm{J}}$, Jaccard index of similarity; $C \mathrm{~s}$, Sorenson index of dissimilarity. 
异和变化, 又反映物种的分化和隔离程度。澜沧江 与怒江水系保护区之间 $\beta_{c}$ 指数的差异大, 反映了不 同水系间的生境差异和变化大; 而怒江水系内不同 保护区(支流)之间 $\beta_{c}$ 指数的差异小, 表明同一水系 内不同支流的生境差异和变化要小得多。水系间或 同一水系的不同支流间, 当生境分化和隔离程度越 大时, 共有种越少, 则 $\beta_{\mathrm{R}}$ 指数越高; 反之, 则 $\beta_{\mathrm{R}}$ 指数 越低。 $\beta_{\mathrm{R}}$ 指数指示整个研究系统中物种分化和隔离 程度(Cody, 1975; Routledge, 1977)。而这种分化的根 本原因在于鱼类的地理分布受到水系的限制, 因此 同水系间鱼类种类的差异不大，而不同水系间鱼类 种类的差异很大(周伟等, 1999; 李风莲等, 2006)。 所以，不同水系间的生境多样性及鱼类隔离程度高 于同一水系内不同支流间的生境多样性及鱼类隔 离程度。地理范围跨度大, 鱼类的栖息生境和分布 空间的异质性高, 则鱼类多样性就高。换个角度看, 保护区的地理纬度、海拔高度、环境的严酷程度和 生物生产力的异同, 均影响鱼类的多样性。不同的 鱼类生态位不尽相同, 有的分布广泛, 有的则分布 狭窄, 这取决于其自身生态位的宽度 (周伟等, 1999)。澜沧江保护区有7个片区，所包含的环境更 加复杂, 纬度跨幅大, 植被变化多样, 这为鱼类的 生存发展提供了有利的条件, 故鱼类多样性比其他 3 个自然保护区更为丰富。

相似性指数反映了鱼类区系组成的渊源关系。 澜沧江水系的澜沧江保护区与怒江水系 3 个自然保 护区的鱼类群落相似性均较小, 揭示了它们分属于 不同的两个水系, 而导致其鱼类的区系组成有着较 大的差异。而同属于怒江水系的南滚河、南捧河及 永德大雪山 3 个自然保护区间鱼类群落相似性均较 高, 其中相似性值最大的是南滚河保护区与南捧河 保护区，根本原因就在于它们不仅同属怒江水系， 而且地理位置又较近。而这 3 个保护区的鱼类相似 性指数随着纬度增加而降低的现象则很好地诠释 了在云南水系中鱼类不同类群呈现出替代性分布 规律的特点(周伟和韩联宪, 2000)。水系主干的下游 江段至上游江段或者与主干不同江段相连、相距较 远的一级支流间, 分布着不同的种类和类群, 鱼类 的组成呈现替代趋势, 存在差异, 有时这种差异还 十分显著。

\section{2 多样性评价指标的深层思考}

生物多样性评价指标如果仅局限于反映分类
阶元的丰富程度和变化情况的 $\alpha$ 和 $\beta$ 多样性指数等, 无疑是非常局限和不完善的。因为这些指标仅着眼 于当前生物种类的丰富程度和种类分布随环境变 化的状况，而不能反映历史渊源、生物演化的历程 和分类群的地位等。只有同时考虑分类阶元的特有 性、单型性和古老性等, 才能全面反映一个区域生 物多样性的起源、地位和价值。

在怒江水系和澜沧江水系的某一江段或支流 中分布着一些狭域特有种、属, 就目前的认知水平 而言, 它们在鱼类群落和生态系统中的作用及经济 价值尚难以判断和估量。但是, 一旦这些阶元的数 量减少或消失, 不仅将造成鱼类多样性及种质资源 无法挽回的巨大损失，同时也将破坏生态系统的稳 定性及物种演化进程和地理分布格局(MacArthur \& Wilson, 1967)。而在对比研究的4个保护区中, 又以 怒江水系的 3 个自然保护区中呈狭域分布的鱼类特 有种多, 所以保护的代表性、意义和价值高, 保护 的责任也更重大。

保护单型性阶元的意义则更加深远和重大。因 为单型性阶元的种群数量减少或消失, 对鱼类物种 多样性及种质资源的损失和对生态系统的影响难 以估量, 保护了某一单型性阶元就意味着保护了该 类群。澜沧江保护区无单型种分布，而怒江水系的3 个自然保护区均有单型种分布, 故对后者实施保 护, 意义更加明显。如保护云纹鳗鲭(Anguilla $n e b u l o s a)$ 相当于保护了鳗鲡科。

本研究结果表明, 怒江水系 3 个自然保护区在 怒江水系鱼类多样性保护中的代表性及保护地位 比澜沧江保护区在澜沧江水系鱼类多样性保护中 的代表性及保护地位相对更高。

\section{3 保护区地理位置及设置思考}

保护区面积大小并非是决定其拥有鱼类多样 性丰富程度的唯一决定因素。从理论上说, 保护区 面积越大及支流越多, 则拥有的鱼类种、属应该越 丰富。这才符合岛屿生物地理学模型的种数-面积 关系(species-area relationship) (MacArthur \& Wilson, 1967)。从表面上看, 澜沧江保护区拥有的鱼类 种、属数量确实如此。但是必须指出, 由于澜沧江 保护区是由7块小保护区构成, 而且主要水域不在 该保护区范围内。从其报告可以看出, 鱼类名录并 不是该保护区自身范围内的鱼类名录，而是将临沧 地区澜沧江中游的所有鱼类汇集在保护区名下，许 
多种类实际是分布于保护区范围之外的。滇西南4 个保护区中，南滚河保护区的面积最小，但其种、 属数量与面积的比值最大; 相反, 澜沧江保护区的 面积最大, 但其种、属数量与面积的比值却最小(表 3)。这一事实给了两个提示, 一是很多类群的物种 丰富度都具有从热带到两极递减的规律(Willig et al, 2003), 南滚河保护区最靠近热带, 故其鱼类多 样性丰富是必然的; 二是生境的异质性极为重要, 南滚河保护区生境异质性高不仅可以容纳更多的 种类，也可为同属物种的分化提供更广阔的空间 (Simberfloff \& Abele, 1976)。

保护区的设置应考虑它们在水系中的位置和 地理纬度。尽管南滚河等3个保护区合起来对怒江 水系的代表性较强, 但它们各自对怒江水系的代表 性并不强。这主要有两个原因: 一是3条一级支流相 互靠得较近, 鱼类的渊源和组成较相近, 生境的同 质性较高; 二是这 3 条一级支流的总流程短或在中 国境内的流程短, 空间异质性还不够高。澜沧江保 护区中也有一定数量的一级支流, 但同样存在相似 的问题。怒江水系 3 个保护区鱼类相似性指数从另 一角度就此问题亦给出了非常明确的提示, 两个保 护区靠得越近, 其相似性指数越高, 拥有相同的 种、属越多; 反之, 则相似性指数越低, 拥有相同的 种、属越少。由此可知, 当保护区之间相距足够远 时, 相似性指数就会降得极低。所以, 选择在大水 系的上、中和下游的一级支流设置保护区就既考虑 了生境的异质性, 又兼顾了地理纬度不同鱼类分类 群的替代性。如果依此思路设置保护区, 那么相应 水系的绝大多数鱼类分类群和种类将得以保护, 当 设置的保护区在数量和面积都相同时, 可以使得保 护区拥有的鱼类种、属具有最大的代表性, 获得最 佳的保护效果。

\section{4 规范保护区日常管理}

鱼类多样性保护在保护区日常管理中的地位 应引起重视。鱼类的活动空间是水域, 水域的连通 性及保护区以外水域的保护是不可忽视的两大因 素。澜沧江保护区所处的位置有漫湾电站和小湾电 站等较大型的水电站, 而在其他 3 个保护区水域及 附近已建、在建或拟建水电站亦不少。因此, 鱼类 的长距离和短距离洄游均已受到阻碍。自然保护区 内、外居民对鱼类的捕捞很少受到限制, 甚至有违 法和毁灭性的捕捞。2009年在南捧河保护区调查时,
保护区管护人员反映，过去他们拥有水域执法权， 可以及时处理一些电鱼、炸鱼和毒鱼的事件。后来 水域执法权转移到农业部门, 当违法事件超出保护 区范围时，他们则不能跨行业和超保护区范围执 法。因此，水电站的规划设计及布局、执法权的规 范等, 需要政府职能部门统筹考虑和协调。目前, 有的地方为了开发利用水资源，兴建水利设施或电 站等, 常常将江河从保护区范围中调出, 以不与现 行法律抵触。这种作法本身就是违反科学的, 因为 江河及生活于其中的水生生物种类也是一个保护 区生态系统中不可或缺的部分。

\section{参考文献}

Chen XY (2013) Checklist of fishes of Yunnan. Zoological Research, 34, 281-343. (in Chinese with English abstract) [陈小勇 (2013) 云南鱼类名录. 动物学研究, 34, 281343.]

Chen XY, Pan XF, Yang JX (2007) Fishes. In: Integrated Scientific Studies on Lancang River Nature Reserve in Yunnan, China (eds Wang J, Du F, Yang YM), pp. 373-407. Science Press, Beijing. (in Chinese) [陈小勇, 潘 晓赋, 杨君兴 (2007) 鱼类. 见: 中国云南澜沧江自然保 护区科学考察研究 (王娟, 杜凡, 杨宇明主编), 373-407. 科学出版社, 北京.]

Chen YR, Cui GH (1989) Summary of ancient fish in Yunnan. Sichuan Journal of Zoology, 8(1), 27-29. (in Chinese) [陈银 瑞, 崔桂华 (1989) 云南古鱼类概述. 四川动物, 8(1), 27-29.]

Chen YY (1998) The Fishes of the Hengduan Mountains Region. Science Press, Beijing. (in Chinese with English abstract) [陈宜瑜 (1998) 横断山区鱼类. 科学出版社, 北 京.]

Chen ZM, Pan XF, Kong DP, Yang JX (2006) Fish biodiversity and its distributional characters during winter in the Dulong River Basin, Yunnan, China. Zoological Research, 27, 505-512. (in Chinese with English abstract) [陈自明, 潘晓 赋, 孔德平, 杨君兴 (2006) 独龙江流域冬季鱼类多样性 及其分布特点. 动物学研究, 27, 505-512.]

Cody ML (1975) Towards a theory of continental species diversity: bird distributions over Mediterranean habitat gradients. In: Ecology and Evolution of Communities (eds Cody ML, Diamond JM), pp. 214-257. Harvard University Press, Cambridge.

Li FL, Li X, Fu Q, Zhou W (2006) Fish diversity in Simao District, Yunnan. Journal of Guangxi Normal University (Natural Science Edition), 24, 77-80. (in Chinese with English abstract) [李凤莲, 李旭, 付蓄, 周伟 (2006) 云南 思茅地区鱼类多样性分析. 广西师范大学学报(自然科学 版), 24, 77-80.]

MacArthur RH, Wilson EO (1967) The Theory of Island Bio- 
geography. Princeton University Press, Princeton.

Magurran AE (1988) Ecological Diversity and Its Measurement. Princeton University Press, New Jersey.

Routledge RD (1977) On Whittaker's components of diversity. Ecology, 58, 1120-1127.

Simberfloff DS, Abele LG (1976) Island biogeography theory and conservation practice. Science (New Series), 191, 285-286.

Su GH, Sha YC, Xiong Y, Zhang PY, Xu J (2015) Changes of functional diversity in fish community before and after a dam closure in the Guanyinyan Hydropower Station. Resources and Environment in the Yangtze Basin, 24, 965-970. (in Chinese with English abstract) [苏国欢, 沙永 翠, 熊鹰, 张培育, 徐军 (2015) 大坝截流前后金沙江观 音岩水电站鱼类群落功能多样性的变化. 长江流域资源 与环境, 24, 965-970.]

Tang FL, Du F, Sun GZ (eds) (2015) Comprehensive Scientific Investigation Research of National Nature Reserve of Nangunhe, Yunnan Province. China Forestry Publishing House, Beijing. (in Chinese) [唐芳林, 杜凡, 孙国政 (主 编) (2015) 云南南滚河国家级自然保护区综合科学考察 研究. 中国林业出版社, 北京.]

Willig MR, Kaufman DM, Steves RD (2003) Latitudinal gradients of biodiversity: pattern, process, scale, and synthesis. Annual Review of Ecology, Evolution, and Systematics, 34, 273-309.

Xiao Q, Yang Z, Tang HY, Duan PX, Wang XQ, Xiao TY, Liu $X Y$ (2015) Species diversity of fish and its conservation in the mainstream of the lower reaches of $\mathrm{Wu}$ River. Biodiversity Science, 23, 499-506. (in Chinese with English abstract) [肖琼, 杨志, 唐会元, 段鹏翔, 王晓清, 肖调义, 刘小燕 (2015) 乌江下游干流鱼类物种多样性及其资源 保护. 生物多样性, 23, 499-506.]
Yang JX, Chen YR, He YH (1994) Studies on fish diversity in plateau lakes of the central Yunnan. Chinese Biodiversity, 2, 204-209. (in Chinese with English abstract) [杨君兴, 陈银 瑞, 何远辉 (1994) 滇中高原湖泊鱼类多样性的研究. 生 物多样性, 2, 204-209.]

Zhou W, Chen YR, Liu N, Zhang Q, Feng CZ (2004) Fishes. In: Nangun River National Nature Reserve of China (eds Yang YM, Du F), pp. 223-235. Yunnan Science and Technology Press, Kunming. (in Chinese) [周伟, 陈银瑞, 刘宁, 张庆, 冯朝忠 (2004) 鱼类. 见: 中国南滚河国家 级自然保护区 (杨宇明, 杜凡主编), 223-235. 云南科技 出版社, 昆明.]

Zhou W, Han LX (2000) Ichthyo-fauna and sustainable utilization of fish resources in Yunnan Lancangjiang River (the upper Mekong). In: China's Biodiversity Conservation Toward the 21th Century (ed. Xu ZH), pp. 282-288. China Forestry Publishing House, Beijing. (in Chinese with English abstract) [周伟, 韩联宪 (2000) 云南澜沧江水系鱼类资源 的保护及持续利用. 见: 面向 21 世纪的中国生物多样性 保护 (许智宏主编), 282-288. 中国林业出版社, 北京.]

Zhou W, Liu JH, Ye XM (1999) A comparison of fish $\beta$ diversity among three branches of Yuanjiang River system, Yunnan. Zoological Research, 20, 111-117. (in Chinese with English abstract) [周伟, 刘菊华, 叶新明 (1999) 云 南元江水系三条支流鱼类 $\beta$ 多样性比较. 动物学研究, 20 , 111-117.]

Zhou XY, Han YH, Gao HW (2011) Study on diversity of fishes in Qinling Ecological Protection Zone. Ecological Science, 30, 624-629. (in Chinese with English abstract) [周 小愿, 韩亚慧, 高宏伟 (2011) 秦岭生态保护区鱼类多样 性研究. 生态科学, 30, 624-629.]

(责任编委: 陈小勇 责任编辑: 问文杰)

\section{附录 Supplementary Material}

\section{附录1 滇西南4个自然保护区鱼类名录}

Appendix 1 A checklist of fishes from four natural reserves in Southwest Yunnan http://www.biodiversity-science.net/fileup/PDF/2015367-1.pdf 
周伟, 李明会, 李有兰. 滇西南四个自然保护区鱼类多样性及评价指标探究. 生物多样性, 2016, 24 (3): 313-320.

http://www. biodiversity-science. net/CN/10.17520/biods.2015367

附录1 滇西南4个自然保护区鱼类名录

Appendix 1 A check list of fishes from four natural reserves in Southwest Yunnan

\begin{tabular}{|c|c|c|c|c|c|}
\hline 物种 Species & $\begin{array}{c}\text { 南滚河保护区 } \\
\text { Nangunhe } \\
\text { Reserve }\end{array}$ & $\begin{array}{c}\text { 南捧河保护区 } \\
\text { Nanpenghe } \\
\text { Reserve }\end{array}$ & $\begin{array}{c}\text { 永德大雪山保 } \\
\text { 护区 Yongde } \\
\text { Daxueshan } \\
\text { Reserve }\end{array}$ & $\begin{array}{c}\text { 澜沧江保护区 } \\
\text { Lancangjiang } \\
\text { Reserve }\end{array}$ & $\begin{array}{lc}\text { 特有性 } & \begin{array}{c}\text { 单型性 } \\
\text { Specific }\end{array} \text { Monotypic }\end{array}$ \\
\hline
\end{tabular}

\section{I 鳗鲟目 ANGUILLIFORMES}

1 鳗鲡科 Anguillidae

1) 云纹鳗鲡 Anguilla nebulosa

\section{II 鲤形目 CYPRINIFORMES}

2 沙鳅科 Botiidae

2) 伊洛瓦底沙鱾 Botia histrionica

3) 长腹华沙鳅 Sinibotia longiventralis

4) 斑鯺连穗沙鳅 Syncrossus beauforti

5) 黑线安巴沙鳅 Ambastaia nigrolineata

\section{3 鳅科 Cobitidae}
6) 伯氏似鳞头鳅
Lepidocephalichthys berdmorei

7) 泥鱾 Misgurnus anguillicaudatus

\section{4 爬鳅科 Balitoridae}

8) 原缨口鳅待定种 Vanmanenia sp.

9) 澜沧江爬鳅 Balitora lancangjiangensis

10) 南汀爬鳅 Balitora nantingensis

11) 长体间吸鳅 Hemimyzon elongatus

12) 怒江间吸鳅 Hemimyzon nujiangensis

13) 彭氏间吸鳅 Hemimyzon pengi

14) 张氏间吸鳅 Hemimyzon zhangi

15) 云南原爬鱾 Balitoropsis yunnanensis

\section{5 条鳅科 Nemacheilidae}

16) 孟定新条鳅 Neonoemacheilus mengdingensis

17) 拟鳗荷马条鳅 Homatula anguillioides

18）多鳞荷马条鳅 Homatula pycnolepis

19) 南方翅条鳅 Pteronemacheilus meridionalis

20) 双江游鳔条鱾 Physoschistura shuangjiangensis

21) 鼓颗南鳅 Schistura bucculenta

22）隐斑南鱾 Schistura cryptofasciata

23) 异斑南鳅 Schistura disparizona

24) 横纹南鱾 Schistura fasciolata

25) 涺南南鳅 Schistura kengtungensis

26) 宽纹南鳅 Schistura latifasciata

27) 长南鱾 Schistura longa

28) 南定南鳅 Schistura nandingensis

29) 密带南鳅 Schistura poculi

30) 宽带南鱾 Schistura prolixifasciata 


\begin{tabular}{|c|c|c|c|c|c|c|}
\hline 物种 Species & $\begin{array}{c}\text { 南滚河保护区 } \\
\text { Nangunhe } \\
\text { Reserve }\end{array}$ & $\begin{array}{c}\text { 南捧河保护区 } \\
\text { Nanpenghe } \\
\text { Reserve }\end{array}$ & $\begin{array}{c}\text { 永德大雪山保 } \\
\text { 护区 Yongde } \\
\text { Daxueshan } \\
\text { Reserve }\end{array}$ & $\begin{array}{c}\text { 澜沧江保护区 } \\
\text { Lancangjiang } \\
\text { Reserve }\end{array}$ & $\begin{array}{l}\text { 特有性 } \\
\text { Specific }\end{array}$ & $\begin{array}{c}\text { 单型性 } \\
\text { Monotypic }\end{array}$ \\
\hline
\end{tabular}

鿕亚科 Danioninae

31) 布朗鳎 Danio browni

32）金线鲗Danio chrysotaeniatus

33) 长嘴鱲 Raiamas guttatus

34) 斑尾低线鱲 Barilius caudiocellatus

35) 丽色低线鱲 Barilius pulchellus

36) 异鲖 Aspidoparia morar

37) 马口鱼 Opsariichthys bidens

鮈亚科 Gobioninae

38) 花鳃 Hemibarbus maculatus

鲃亚科 Barbinae

39) 侧带结鱼 Tor laterivittatus

40) 中国结鱼 Tor sinensis

41) 野结鱼 Tor tambra

42) 斑尾小鲃 Puntius sophore

43) 异斑小鲃 Puntius ticto

44) 南方白甲鱼 Onychostoma gerlachi

45) 少鳞舟齿鱼 Scaphiodonichthys acanthopterus

46)云南吻孔鲃 Poropuntius huangchuchieni

47) 后鯺吻孔鲃 Poropuntius opisthopterus

48) 后背鲈鲤 Percocypris pingi retrodorslis

49) 保山新光唇鱼 Neolissochilus baoshanensis

野鲮亚科 Labeoninae

50) 孟加拉鲮 Bangana sp.

51) 脂孟加拉鲮 Bangana lippa

52) 云南孟加拉鲮 Bangana yunnanensis

53) 朱氏孟加拉鲮 Bangana zhui

54) 皮氏野鲮 Labeo pierrei

55) 缅甸穗唇鲃 Crossocheilus burmanicus

56) 奇额墨头鱼 Garra mirofronits

57) 怒江墨头鱼 Garra nujiangensis

58) 萨尔温墨头鱼 Garra salweenica

裂腹鱼亚科 Schizothoracinae

59) 光唇裂腹鱼 Schizothorax lissolabiatus

60) 怒江裂腹鱼 Schizothorax nukiangensis

61) 云南裂腹鱼

Schizothorax yunnanensis yunnanensis

鲤亚科 Cyprininae

62) 鲫 Carassius auratus

\section{III 鲇形目 SILURIFORMES}

\section{7 胡子鲇科 Clariidae}

63) 胡子鲇 Clarias fuscus

\section{8 锡伯鲇科 Schilbidae}

64) 长慰鲱鲇 Clupisoma longianalis

65) 中华鲱鲇 Clupisoma sinense

\section{9 鮡科 Sisoridae}

66) 鮕 Bagarius bagarius

67) 巨鮕 Bagarius yarrelli 


\begin{tabular}{|c|c|c|c|c|c|c|c|}
\hline 物种 Speci & & $\begin{array}{c}\text { 南滚河保护区 } \\
\text { Nangunhe } \\
\text { Reserve }\end{array}$ & $\begin{array}{c}\text { 南捧河保护区 } \\
\text { Nanpenghe } \\
\text { Reserve }\end{array}$ & $\begin{array}{c}\text { 永德大雪山保 } \\
\text { 护区 Yongde } \\
\text { Daxueshan } \\
\text { Reserve } \\
\end{array}$ & $\begin{array}{c}\text { 澜沧江保护区 } \\
\text { Lancangjiang } \\
\text { Reserve }\end{array}$ & $\begin{array}{l}\text { 特有性 } \\
\text { Specific }\end{array}$ & $\begin{array}{c}\text { 单型性 } \\
\text { Monotypic }\end{array}$ \\
\hline & 缅甸纹胸鮡 Glyptothorax burmanicus & + & + & + & & $E_{N}$ & \\
\hline 69) & 异色纹胸鮡 Glyptothorax fucatus & + & + & + & & $\mathrm{E}_{1}$ & \\
\hline 70) & 纺锤纹胸鮡 Glyptothorax fuscus & & & & + & $\mathrm{E}_{\mathrm{L}}$ & \\
\hline 71) & 老挝纹胸鮡 Glyptothorax laosensis & & & & + & & \\
\hline 72) & 大斑纹胸鮡 Glyptothorax macromaculatus & & & & + & $\mathrm{E}_{\mathrm{L}}$ & \\
\hline 73) & 似亮背纹胸鮡 Glyptothorax ngapang & + & + & + & & & \\
\hline 74) & 三线纹胸鮡 Glyptothorax trilineatus & + & + & + & & & \\
\hline 75) & 长须纹胸鮡 Glyptothorax longinema & + & + & + & + & & \\
\hline & 少斑褶鮡 Pseudecheneis paucipunctatus & + & & & & $\mathrm{E}_{1}$ & \\
\hline & 长鯺禇鮡 Pseudecheneis longipectoralis & & + & + & & $E_{N}$ & \\
\hline 78) & 似黄斑褶鮡 Pseudecheneis sulcatoides & & & & + & $\mathrm{E}_{\mathrm{L}}$ & \\
\hline 79) & 景东异齿鰋 Oreoglanis jingdongensis & & & & + & $E_{L}$ & \\
\hline 80) & 无斑异齿鰋 Oreoglanis immaculatus & + & & + & & $\mathrm{E}_{1} \mathrm{E}_{3}$ & \\
\hline 81) & 穗缘异齿鰋 Oreoglanis setiger & & & & + & $E_{L}$ & \\
\hline \multicolumn{8}{|c|}{ IV 领针鱼目 BELONIFORMES } \\
\hline \multicolumn{8}{|c|}{10 怪领鲜科 Adrianichthyidae } \\
\hline & 中华青鲟 Oryzias sinensis & & & & + & & \\
\hline \multicolumn{8}{|c|}{$\mathrm{V}$ 合鳃鱼目 SYNBRANCHIFORMES } \\
\hline \multicolumn{8}{|c|}{11 合鳃鱼科 Synbranchidae } \\
\hline & 黄䲕 Monopterus albus & + & + & + & + & & \\
\hline \multicolumn{8}{|c|}{12 刺鳅科 Mastacembelidae } \\
\hline 84) & 大刺鳅 Mastacembelus armatus & + & + & + & + & & \\
\hline \multicolumn{8}{|c|}{ VI 鲇形目 PERCIFORMES } \\
\hline \multicolumn{8}{|c|}{13 鳢科 Channidae } \\
\hline 85) & 宽额鳢 Channa gachua & + & + & + & + & & \\
\hline \multicolumn{2}{|c|}{ 合计 Total } & 33 & 41 & 35 & 54 & & \\
\hline
\end{tabular}

Mg: 单型属; Ms: 单型种; $\mathrm{E}_{\mathrm{L}}$ : 澜沧江水系特有种; $\mathrm{E}_{\mathrm{N}}$ : 怒江水系特有种; $\mathrm{E}_{1}$ : 南滚河保护区分布的特有种; $\mathrm{E}_{2}$ : 南捧河保护区分布的特有种; $\mathrm{E}_{3}$ : 永德大雪山保护区分布的特有种。

Mg, Monotypic genus; Ms, Monotypic species; $E_{L}$, Endemic species occurred in Lancangjiang System; $E_{N}$, Endemic species occurred in Nujiang System; $E_{1}$, Endemic species occurred in Nangunhe Reserve; $E_{2}$, Endemic species occurred in Nanpenghe Reserve; $E_{3}$, Endemic species occurred in Yongde Daxueshan Reserve. 